\title{
The effects of sildenafil citrate on feto-placental development and haemodynamics in a rabbit model of intrauterine growth restriction
}

\author{
Jorge López-Tello, Marı́a Arias-A’' Ivarez, Maria-Án ngeles Jiménez-Martı \\ 'nez, Alicia Barbero-Fernández, Rosa Marı́a García-García, Marı́a Rodrı \\ 'guez, Pedro L. Lorenzo, Laura Torres-Rovira, Susana Astiz, \\ Antonio Gonza'lez-Bulnes and Pilar G. Rebollar
}

\begin{abstract}
The present study evaluated the effectiveness of sildenafil citrate (SC) to improve placental and fetal growth in a diet-induced rabbit model of intrauterine growth restriction (IUGR). Pregnant rabbits were fed either ad libitum (Group C) or restricted to 50\% of dietary requirements (Group R) or restricted and treated with SC (Group SC). The treatment with SC improved placental development by increasing vascularity and vessel hypertrophy in the decidua. The assessment of feto-placental haemodynamics showed higher resistance and pulsatility indices at the middle cerebral artery (MCA) in fetuses treated with SC when compared with Group R, which had increased systolic peak and time-averaged mean velocities at the MCA. Furthermore, fetuses in the SC group had significantly higher biparietal and thoracic diameters and longer crown-rump lengths than fetuses in Group R. Hence, the SC group had a reduced IUGR rate and a higher kit size at birth compared with Group R. In conclusion, SC may provide potential benefits in pregnancies with placental insufficiency and IUGR, partially counteracting the negative effects of food restriction on placental development and fetal growth. However, the present study also found evidence of a possible blood overflow in the brain that warrants further investigation.
\end{abstract}

\section{Introduction}

The failure of fetuses to achieve their full growth potential is known as intrauterine growth restriction (IUGR). Currently, between 5 and $10 \%$ of human infants undergo IUGR (Nardozza et al. 2012) and, as a consequence, are at greater risk of neonatal health disorders (Maršál 2002) and late-onset diseases in adulthood (Ross and Desai 2013). The aetiology of IUGR is multifactorial and scarcely understood, but is thought to include a combination of maternal, environmental, fetal and placental factors negatively affecting fetal homeostasis (Sankaran and Kyle 2009).
The intrauterine environmental conditions of the fetus are regulated by the placenta. At present, more than $60 \%$ of IUGR offspring in developed countries are linked to abnormal placental development or placental insufficiency (Ghidini 1996). Thus, research has been focussed on devising preventive and therapeutic strategies for IUGR and, specifically, on developing therapies to improve placental development and utero-placental blood flow. An encouraging area of research is the stimulation of the placental pro-angiogenic factors placental growth factor (PIGF) and vascular endothelial growth factor (VEGF), which are primarily driven by nitric oxide (NO) and its endothelial 
constitutive synthase (eNOS or NOS3). NO is a potent stimulator of vasodilatation and angiogenesis during placental development (Purcell et al. 1999) and decreased NO bioavailability is recognised to be involved in the pathogenesis of IUGR (Serrano et al. 2004). Based on this, a possible therapeutic strategy would be the administration of sildenafil citrate (SC), a vasodilator molecule that enhances NO concentrations by inhibiting phosphodiesterase-5 (PDE-5) activity (Chuang et al. 1998), which may optimise placental function and, therefore, alleviate IUGR in at-risk pregnancies. After preclinical studies, SC is being tested in women with promising results, improving maternal and fetal blood flow velocimetry and fetal well being (Lacassie et al. 2004; Lin et al. 2012; Panda et al. 2014; Sun et al. 2014; Trapani et al. 2015). Currently, several clinical trials are underway to further test the usefulness and safety of SC treatments for IUGR (Ganzevoort et al. 2014).

Research in human pregnancies is obviously limited by ethical and practical limitations and necessitates the use of animal models. Most studies of IUGR have been performed in rodent models (Schroder 2003). However, the rabbit is an emergent and complementary model for pregnancy studies (Eixarch et al. 2009; Püschel et al. 2010). The size of a rabbit allows serial blood sampling and imaging and also shows more similarities in metabolic, endocrine, placental and fetal features to humans than rodents (Kobayashi et al. 2011; Fischer et al. 2012; Malassiné et al. 2013). Specifically, the rabbit placenta is haemodichorial, which is more physiologically similar to the haemomonochorial human placenta than the haemotrichorial placenta of rodents (Fischer et al. 2012). Haemodynamic changes in the placenta during pregnancy in rabbits are also comparable to those in humans (Fischer et al. 2012; Lecarpentier et al. 2012), with high blood flow velocities in the umbilical arteries resembling human values in the second trimester (Polisca et al. 2010). Additionally, brain white-matter maturation in rabbits occurs during the perinatal period, similarly to humans, whilst in rodents this process occurs largely in the postnatal period (Beaudoin et al. 2003; Derrick et al. 2009).

Different studies in rodent models have demonstrated that SC administration during pregnancy prevents the production of inflammatory cytokines, prevents fetal loss (Luna et al. 2015), improves feto-placental blood flow (Stanley et al. 2012) and increases fetal weight (Stanley et al. 2012; Dilworth et al. 2013). However, most of the results were obtained post mortem and the ontogeny of changes in feto-placental haemodynamics and intrauterine growth are unknown.

Hence, the present study evaluated whether maternal SC administration could improve or ameliorate diet-induced defects in feto-placental development, haemodynamics and offspring outcome seen in rabbits exposed to $50 \%$ food restriction from Day 9 of pregnancy onwards, a model previously developed in our laboratory (López-Tello et al. 2015).

\section{Materials and methods}

\section{Ethical approval}

All experiments were carried out at the animal facilities of the Polytechnic University of Madrid (UPM, Spain), which meet the requirements of the European Union for scientific procedure establishments, under project licence of the UPM Scientific Ethic Committee. Animal manipulations were performed in accordance with the Spanish policy for animal protection RD53/ 2013, which complied with the European Union Directive about the protection of animals used in experimentation.

\section{Animals and management}

The experiment involved 45 New Zealand $\times$ California White rabbits (Oryctolagus cuniculus). Females were previously artificially inseminated and during the trial the animals were kept in individual cages under a constant photoperiod of $16 \mathrm{~h}$ light per day. A temperature of $18-22^{\circ} \mathrm{C}$ and a relative humidity of 60 $75 \%$ were maintained by a forced ventilation system, according to the normal husbandry conditions for rabbits (Rebollar et al. 2012). All females had free access to water and were fed a diet containing $16 \%$ crude protein, $37 \%$ crude fibre, $3.7 \%$ fat and crude energy content of $2400 \mathrm{kcal} \mathrm{kg}^{-1}$ (Nanta, Spain). Daily food intake of dams was determined individually (2 weeks before starting the experiment). Food intake was measured daily by weighing the food and feeder at the beginning and at the end of the adjustment period. The mean food intake of all dams was $187.0 \pm 11.0 \mathrm{~g} \mathrm{day}^{-1}$.

\section{Experimental design}

At Day 9 of pregnancy (term = Day 31), females were randomly distributed into three experimental groups. The first group was fed ad libitum during the entire pregnancy and considered to be the control group (Group C; $n=15$ ), whilst the remaining dams were restricted individually to $50 \%$ of their average daily food intake until parturition. From Day 22 of pregnancy to delivery, half of the restricted dams were treated daily with oral SC. This was prepared by grinding Viagra tablets $(100 \mathrm{mg}$; Pfizer, USA; $5 \mathrm{mg} \mathrm{kg}^{-1}$ excluding excipients) and mixing in $1 \mathrm{~mL}$ of baby food (Hero Baby, Spain; Group SC, $n=15$ ). The remaining restricted dams received no other treatment and were considered as the untreated controls of food restriction (Group R, $n=15$ ). Day 22 was chosen because it corresponds to the beginning of the period in pregnancy in which enlargement of the uterus ceases, the somatic circulation rate decreases and the incidence of IUGR is augmented due to the increase in the requirements of the fetuses for oxygen and nutrients (Reynolds 1946; LópezTello et al. 2015). The SC dose used in this trial was adjusted according to previous studies performed in rabbits and rats (Park et al. 2004; Cauli et al. 2010) and it was administrated orally with a syringe once per day (0900 hours) to ensure that each animal received the adequate dose, avoiding any under- or overdosing. The use of a unique dose per day was based on the protocols of Sánchez-Aparicio et al. (2008) in guinea pigs and guidelines from the FDA Center for Drug Evaluation and Research in pregnant rabbits (http://www.accessdata.fda.gov/ drugsatfda_docs/NDA/98/viagra/pharm_tox_pp_117_114.pdf, verified 28 April 2016). Both control groups (C and R) also received $1 \mathrm{~mL}$ of baby food at the same time as treated dams to avoid any possible confounding effect.

Four days after SC administration (Day 26 of pregnancy; $\approx 84 \%$ of the total pregnancy), four females of each group were randomly submitted to a Doppler evaluation. At Day 28 of 
pregnancy ( $\approx 90 \%$ of the total pregnancy), 22 dams were killed to study feto-placental morphology and the remaining females were allowed to deliver, registering data from newborns.

\section{Study of fetuses and placentas}

The dams were sedated with $35 \mathrm{mg} \mathrm{kg}^{-1}$ ketamine (Imalgene1000; Merial, Spain) and then killed using an intravenous bolus of barbiturate ( $30 \mathrm{mg} \mathrm{kg}^{-1}$; Dolethal; Vetoquinol, Spain). A mid-ventral abdominal laparotomy was made to remove the entire reproductive tract. Fetuses were dissected from their extra-embryonic membranes and considered as either: (1) viable fetus (presented natural morphological features according to age and bodyweight; see Fig. S1a, available as Supplementary Material to this paper), (2) mummified or dead fetus (excluded from trial as we could not determinate the exact time of death; Fig. S1b) or (3) resorption (with atrophied fetal and maternal placenta; Fig. S1c).

For the viable fetuses, placentas were immediately and gently separated from the decidua (attached to the endometrium and comprised of uninucleated and giant cells in a matrix of collagen in which maternal blood passes to the implantation site through spiral arteries; Samuel et al. 1975) and the labyrinth (mainly composed of fetal and maternal capillaries and trophoblast responsible for nutrient and oxygen exchange; Fig. S1d). Both compartments were weighed and the length and thickness measured using slide calipers (values were obtained by considering the average of three consecutive measurements). Following this, fetuses were weighed and measured for crown-rump length (CRL, maximum distance from crown to tail), biparietal diameter (BPD, length from one parietal eminence to the other) and transversal thoracic diameter (TD, length at the diaphragm insertion). Fetuses were beheaded at the atlanto-occipital joint and, after cranial opening and medial laparotomy, fetal brain and liver were removed and weighed.

A viable fetus was considered to have been exposed to IUGR when its bodyweight was below the 10th percentile, assuming the control group as our standard value. Afterwards, different ratios were obtained by dividing fetal (head, brain and liver) and placental structures (decidua and labyrinth zones) by fetal weight. The weight of the brain relative to the liver was also considered as an indicator of IUGR. Finally, in order to evaluate fetal metabolic status, a total of 30 fetuses from each group were randomly selected. Blood samples were obtained after decapitation and placed in tubes with ethylenediamine tetraacetic acid (EDTA), centrifuged at $1200 \mathrm{~g}$ for $10 \mathrm{~min}$ at $4^{\circ} \mathrm{C}$ to obtain plasma and immediately stored at $-20^{\circ} \mathrm{C}$ until analysis. Parameters related to the metabolism of glucose and lipids (triglycerides and cholesterol) were measured with a clinical chemistry analyser (Saturno 300 plus; Crony Instruments, Italy) according to the manufacturer's instructions.

\section{Placental histopathology}

Sections of placentas and uteri adjacent to the ovary were collected ( $n=10$ per group), fixed in $4 \%$ paraformaldehyde for $24 \mathrm{~h}$ and switched to $70 \%$ ethanol for histological evaluation. Samples were embedded in paraffin, sectioned at $4-\mu \mathrm{m}$ thickness and stained with haematoxylin-eosin following routine laboratory procedures. Sections were examined histologically by a trained pathologist blinded for the experimental procedure.

\section{Feto-placental haemodynamics}

Ultrasound scanning was carried out with a Vivid-I ultrasound machine equipped with a multi-frequency $(8-12 \mathrm{MHz})$ linear array probe (General Electrics Ultraschall Deutschland $\mathrm{GmbH}$, Germany). In brief, fasted animals were shaved at the abdominal area and gently restrained in dorsal recumbence, without anaesthesia to avoid any effect on heart rate and blood flow during the observations. Females usually stayed calm and relaxed during the procedure since they were regularly handled by research staff. A complete scan of the dam did not last more than $20 \mathrm{~min}$. Measurements were taken from 48 fetuses (four fetuses from each female in order to minimise individual effects).

Blood-flow parameters of umbilical cord arteries (UCA) and middle cerebral arteries (MCA) were determined after identifying the vessels with colour Doppler. The waveforms of three consecutive cardiac cycles in each vessel were recorded, disregarding views with angles of insonation between 20 and $60^{\circ}$. Measurements were obtained after the entire examination, recording and including resistance index (RI), pulsatility index (PI), systolic peak velocity (SPV), end diastolic velocity (EDV) and time-averaged mean velocity (MV), measured at both UCA and MCA.

\section{Neonatal study}

Twenty-three dams were allowed to deliver in order to study the effects of food restriction and SC administration during pregnancy on the neonates. Immediately after birth, all the kits $(n=251)$ were classified as viable newborns $(n=236)$ or stillborns $(n=15)$. Bodyweight and morphometric parameters (CRL, BPD and TD) were measured only in viable newborns. A newborn was considered to have IUGR when its bodyweight was below the 10th percentile assuming the control group at birth as our standard value.

\section{Statistical analysis}

Statistical analyses were performed with Statistical Analysis System Software (SAS Institute Inc. Cary, NC, USA). Effects of undernutrition and sildenafil treatment on the morphological parameters of fetuses, placentas and newborns and the haemodynamic parameters of fetuses were assessed by one-way analysis of variance (one-way ANOVA); $t$-test was performed to contrast the differences between groups. The number of fetuses or kits per dam was used as a covariate. Possible differences in IUGR rate and number of placentas with histological findings were calculated by a $\chi^{2}$ test. All data are reported as mean \pm s.e.m. and probabilities were considered to be significant at $P<0.05$.

\section{Results}

Morphological study of fetuses and placentas

The number of total $(\mathrm{C}, 11.95 \pm 0.77 ; \mathrm{R}, 12.70 \pm 0.70$; SC, $12.75 \pm 0.75)$, viable $(C, 11.55 \pm 0.78 ; R, 11.60 \pm 0.71 ; S C$, $11.59 \pm 0.76)$ and mummified $(C, 0.15 \pm 0.14 ; R, 0.22 \pm 0.19$; $\mathrm{SC}, 0.13 \pm 0.13)$ fetuses and resorptions $(\mathrm{C}, 0.25 \pm 0.20$; 
Table 1. Morphometric study of fetuses at Day 28 of pregnancy from dams fed ad libitum (C), restricted diet $(\mathrm{R})$ or restricted diet and treated with sildenafil citrate (SC)

Statistical analyses were performed by one-way ANOVA and $t$-test mean comparison test. IUGR rate defined as those fetuses under 10th percentile of ad libitum control weights ( $32 \mathrm{~g}$ ) estimated by a $\chi^{2}$ test. Data represented as mean \pm s.e.m. ${ }^{\text {a,b,c }}$ Different superscripts within a row indicate significant differences between groups; $P<0.05$

\begin{tabular}{|c|c|c|c|c|}
\hline Parameter & $\mathrm{C}(n=81)$ & $\mathrm{R}(n=94)$ & $\mathrm{SC}(n=77)$ & $P>\mathrm{f}$ \\
\hline \multicolumn{5}{|l|}{ Morphometric measurements } \\
\hline Biparietal diameter $(\mathrm{cm})$ & $1.76 \pm 0.02^{\mathrm{a}}$ & $1.67 \pm 0.02^{\mathrm{b}}$ & $1.82 \pm 0.02^{\mathrm{c}}$ & 0.001 \\
\hline Crown-rump length $(\mathrm{cm})$ & $10.52 \pm 0.08^{\mathrm{a}}$ & $9.95 \pm 0.07^{\mathrm{b}}$ & $10.32 \pm 0.08^{\mathrm{a}}$ & 0.001 \\
\hline Thoracic diameter $(\mathrm{cm})$ & $1.82 \pm 0.02^{\mathrm{a}}$ & $1.63 \pm 0.02^{\mathrm{b}}$ & $1.70 \pm 0.02^{\mathrm{c}}$ & 0.001 \\
\hline \multicolumn{5}{|l|}{ Fetus weights } \\
\hline Total (g) & $39.28 \pm 0.64^{\mathrm{a}}$ & $33.91 \pm 0.59^{\mathrm{b}}$ & $34.30 \pm 0.66^{\mathrm{b}}$ & 0.001 \\
\hline Head $(\mathrm{g})$ & $9.46 \pm 0.15^{\mathrm{a}}$ & $8.47 \pm 0.14^{\mathrm{b}}$ & $8.67 \pm 0.16^{\mathrm{b}}$ & 0.001 \\
\hline Body (g) & $29.50 \pm 0.52^{\mathrm{a}}$ & $25.34 \pm 0.49^{\mathrm{b}}$ & $25.44 \pm 0.54^{\mathrm{b}}$ & 0.001 \\
\hline Liver $(\mathrm{g})$ & $2.90 \pm 0.07^{\mathrm{a}}$ & $2.52 \pm 0.07^{\mathrm{b}}$ & $2.63 \pm 0.08^{\mathrm{b}}$ & 0.001 \\
\hline Brain (g) & $1.05 \pm 0.01^{\mathrm{a}}$ & $0.99 \pm 0.01^{\mathrm{b}}$ & $1.00 \pm 0.01^{\mathrm{b}}$ & 0.001 \\
\hline \multicolumn{5}{|l|}{ Weight ratios } \\
\hline Head weight $(\%)$ & $24.22 \pm 0.32^{\mathrm{a}}$ & $25.36 \pm 0.30^{\mathrm{b}}$ & $25.40 \pm 0.33^{\mathrm{b}}$ & 0.015 \\
\hline Brain ratio $(\%)$ & $2.74 \pm 0.05^{\mathrm{a}}$ & $3.05 \pm 0.04^{\mathrm{b}}$ & $2.94 \pm 0.05^{\mathrm{b}}$ & 0.001 \\
\hline Liver ratio (\%) & $7.34 \pm 0.14^{\mathrm{a}}$ & $7.32 \pm 0.13^{\mathrm{a}}$ & $7.74 \pm 0.14^{\mathrm{b}}$ & 0.035 \\
\hline Brain : liver ratio $(\%)$ & $38.66 \pm 1.16^{\mathrm{a}}$ & $43.65 \pm 1.09^{\mathrm{b}}$ & $39.01 \pm 1.19^{\mathrm{a}}$ & 0.002 \\
\hline IUGR rate $(\%)$ & $9.87^{\mathrm{a}}$ & $44.68^{\mathrm{b}}$ & $29.87^{\mathrm{c}}$ & 0.001 \\
\hline
\end{tabular}

$\mathrm{R}, 0.27 \pm 0.19 ; \mathrm{SC}, 0.27 \pm 0.20)$ were similar among groups. All the values for morphometric measurements were lower in Group R than in Group C $(P<0.05$; Table 1). Conversely, the $\mathrm{BPD}$ of the SC group was higher than in Groups $\mathrm{C}$ and $\mathrm{R}$ $(P<0.05)$, whilst the CRL was similar to Group $\mathrm{C}$ and greater than Group R. For the SC group, the TD was lower than Group C but greater than Group R. Food restriction (Groups R and SC) reduced the weight of fetuses as well as the weight of head, body, liver and brain when compared with Group $\mathrm{C}(P<0.05)$. However, SC administration was associated with an intermediate value of IUGR rate when compared with Groups C and R (Table 1 and Fig. S2). The ratios of head and brain to fetal weight (Table 1) were significantly higher in Groups R and SC $(P<0.05)$, whilst the brain to liver weight ratio was only higher in Group $\mathrm{R}(P<0.05)$. In contrast, the ratio of liver to fetal weight was higher only in Group SC $(P<0.05)$.

With regards to metabolic status, fetuses from Group SC presented higher plasma glucose concentrations compared with Groups C and R $(104.23 \pm 6.72$ vs $76.91 \pm 8.49$ and $79.35 \pm 6.84 \mathrm{mg} \mathrm{dL}^{-1}$, respectively; $P<0.05$ ). However, no differences in plasma cholesterol $(\mathrm{C}, 85.17 \pm 4.22 ; \mathrm{R}, 81.84 \pm$ 3.32; SC, $84.64 \pm 3.28 \mathrm{mg} \mathrm{dL}^{-1}$ ) or triglyceride concentrations (C, $116.90 \pm 7.05 ; \mathrm{R}, 116.84 \pm 5.70 ; \quad \mathrm{SC}, 112.01 \pm$ $5.87 \mathrm{mg} \mathrm{dL}^{-1}$ ) were found among groups.

Maternal food restriction was also found to be related to changes in placental development in both the decidua and the labyrinth compartment (Table 2). The decidua was significantly thinner in Group R, whereas placentas in the group treated with $\mathrm{SC}$ had similar values to Group C. On the other hand, there was a trend for a thicker labyrinth in Group SC than in Group R $(P=0.08)$. The food restriction in both SC and $\mathrm{R}$ groups reduced the length of decidua and labyrinth, but did not affect compartment weight. Finally, the weight of the placenta relative to fetal weight, total placental ratio, was significantly higher in Group SC than in Group C $(P<0.05)$. The ratio between the decidua and fetal weight for Group SC showed intermediate values between Groups $\mathrm{C}$ and $\mathrm{R}$, whilst the labyrinth to fetal weight ratio was significantly higher in Group SC when compared with the other two groups $(P<0.05)$.

\section{Placental histopathology}

Significant histological findings are summarised in Table 3 and Fig. 1. Histological changes in the placental structure were found in the junction zone and decidua region of both restricted groups ( $\mathrm{R}$ and $\mathrm{SC}$ ). The junction zones of a high percentage of placentas from Group $\mathrm{R}$ contained moderately increased amounts of poorly cellular fibrous connective tissue that extended multi-focally into the labyrinth and surrounds, and replaced vascular channels with the collapse of the adjacent labyrinth structure. Additionally, the decidua from the animals of Group R was moderately thinned when compared with the C and $\mathrm{SC}$ groups. On the other hand, there was a higher percentage of labyrinth and decidua samples containing moderately to markedly increased numbers of dilated small capillaries, venules and arterioles in the SC group. Interestingly, these placentas presented a higher number of and more dilated arterial sinuses compared with placentas from control and restricted animals without treatment.

\section{Feto-placental haemodynamics}

The results obtained at Day 26 of pregnancy showed a trend for higher RI $(P=0.06)$ and a significantly higher SPV $(P<0.05)$ in the UCA in both restricted groups with respect to fetuses from Group C (Table 4). There were significant effects of SC treatment on the blood flow in the fetal MCA, with fetuses in 
Table 2. Placental dimensions obtained at Day 28 of pregnancy in dams fed ad libitum (C), restricted diet (R) or restricted diet and treated with sildenafil citrate (SC)

Statistical analyses were performed by one-way ANOVA and $t$-test mean comparison test. Data represented as mean \pm s.e.m. IUGR rate estimated by a $\chi^{2}$ test. ${ }^{\mathrm{a}, \mathrm{b}}$ Different superscripts within a row indicate significant differences between groups; $P<0.05$

\begin{tabular}{lcccc}
\hline Parameter & $\mathrm{C}(n=81)$ & $\mathrm{R}(n=94)$ & $\mathrm{SC}(n=77)$ & $P>\mathrm{f}$ \\
\hline Total placental weight (g) & $5.62 \pm 0.16$ & $5.28 \pm 0.15$ & $5.27 \pm 0.16$ & 0.205 \\
Total placental weight/fetal weight (\%) & $14.74 \pm 0.41^{\mathrm{a}}$ & $15.57 \pm 0.37^{\mathrm{ab}}$ & $16.01 \pm 0.40^{\mathrm{b}}$ & 0.030 \\
Decidual zone & & & \\
$\quad$ Weight (g) & $1.28 \pm 0.04$ & $1.24 \pm 0.04$ & $1.15 \pm 0.04$ & 0.100 \\
$\quad$ Length (cm) & $3.65 \pm 0.09^{\mathrm{a}}$ & $3.23 \pm 0.09^{\mathrm{b}}$ & $3.36 \pm 0.10^{\mathrm{b}}$ & 0.006 \\
Thickness (cm) & $0.32 \pm 0.02^{\mathrm{a}}$ & $0.26 \pm 0.02^{\mathrm{b}}$ & $0.35 \pm 0.02^{\mathrm{a}}$ & 0.001 \\
$\quad$ Decidua weight/fetal weight (\%) & $3.41 \pm 0.16^{\mathrm{a}}$ & $3.88 \pm 0.15^{\mathrm{b}}$ & $3.49 \pm 0.16^{\mathrm{a}}$ & 0.038 \\
Labyrinth zone & & & & \\
$\quad$ Weight (g) & $3.93 \pm 0.14$ & $3.64 \pm 0.13$ & $3.8 \pm 0.14$ & 0.323 \\
$\quad$ Length (cm) & $3.61 \pm 0.06^{\mathrm{a}}$ & $3.27 \pm 0.05^{\mathrm{b}}$ & $3.34 \pm 0.06^{\mathrm{b}}$ & 0.001 \\
Thickness (cm) & $0.47 \pm 0.02$ & $0.43 \pm 0.01$ & $0.48 \pm 0.02$ & 0.084 \\
$\quad$ Labyrinth weight/fetal weight (\%) & $10.27 \pm 0.34^{\mathrm{a}}$ & $10.62 \pm 0.31^{\mathrm{a}}$ & $11.53 \pm 0.34^{\mathrm{b}}$ & 0.029 \\
\hline
\end{tabular}

Table 3. Characteristic placental histology at Day 28 of pregnancy in dams fed ad libitum (C), restricted diet $(\mathrm{R})$ or restricted diet treated with sildenafil citrate (SC)

Statistical analyses were performed by $\chi^{2}$ test. Data represented as mean \pm s.e.m. ${ }^{\mathrm{a}, \mathrm{b}}$ Different superscripts within a row indicate significant differences between groups; $P<0.05$ (number of placentas with findings compared with the total number of samples)

\begin{tabular}{lrrrr}
\hline Parameter & $\mathrm{C}(n=10)$ & $\mathrm{R}(n=10)$ & $\mathrm{SC}(n=10)$ & $P>\mathrm{f}$ \\
\hline $\begin{array}{l}\text { Labyrinth zone } \\
\quad \text { Collapse and } \\
\quad \text { fibrosis (\%) }\end{array}$ & $10^{\mathrm{a}}(1 / 10)$ & $50^{\mathrm{b}}(5 / 10)$ & $0^{\mathrm{a}}(0 / 10)$ & 0.009 \\
$\begin{array}{l}\text { Junctional zone } \\
\text { Fibrosis (\%) }\end{array}$ & & & & \\
$\quad$ Increased & $10^{\mathrm{a}}(1 / 10)$ & $6^{\mathrm{b}}(6 / 10)$ & $0^{\mathrm{a}}(0 / 10)$ & 0.001 \\
$\quad 0^{\mathrm{a}}(0 / 10)$ & $0^{\mathrm{a}}(0 / 10)$ & $80^{\mathrm{b}}(8 / 10)$ & 0.001 \\
$\begin{array}{l}\text { Decidual zone } \\
\text { Atrophy (\%) }\end{array}$ & & & & \\
$\quad$ Hyperplastic & & & & \\
$\quad$ arterial sinuses (\%) & $0^{\mathrm{a}}(0 / 10)$ & $70^{\mathrm{b}}(7 / 10)$ & $0^{\mathrm{a}}(0 / 10)$ & 0.001 \\
\hline
\end{tabular}

Group SC showing higher RI and PI than those from the other two groups $(P<0.05)$. SPV and MV measurements were also higher in the SC group than for fetuses in Group $\mathrm{C}(P<0.05)$.

\section{Neonatal morphological study}

At parturition, no significant differences in the total number of kits delivered (C, 11.62 \pm 0.88 ; R, 11.28 \pm 1.01 ; SC, 9.72 \pm 1.37 ), newborns $(\mathrm{C}, 10.62 \pm 0.84$; $\mathrm{R}, 10.71 \pm 0.92$; $\mathrm{SC}, 9.28 \pm 1.25)$ or stillborns (C, $1 \pm 0.62 ; \mathrm{R}, 0.57 \pm 0.30 ; \mathrm{SC}, 0.42 \pm 0.30)$ were found. Group $\mathrm{C}$ had the highest values for average bodyweight and morphometric measurements of BPD, CRL and TD $(P<0.05)$, whereas SC kits showed intermediate values between Groups C and $\mathrm{R}$ for all morphometric parameters studied except fetal weight. Food restriction significantly increased the rate of newborn IUGR $(P<0.05$; Table 5 and Fig. S3), whilst values obtained from the group with $\mathrm{SC}$ administration were intermediate between Groups $\mathrm{C}$ and $\mathrm{R}$.

\section{Discussion}

The results of the present study in a rabbit model support the usefulness of treatment with sildenafil citrate to alleviate states of placental dysfunction and improve body size in fetuses affected by IUGR.

In the present trial, sildenafil citrate therapy favoured placental growth and vascularisation, lowered IUGR incidence and resulted in offspring with increased birth size (in terms of higher values of crown-rump length and biparietal and thoracic diameters). Our results support previous data showing that maternal undernutrition during pregnancy or defects in placental development have negative effects on fetal homeostasis and give way to the appearance of IUGR (Lesage et al. 2001; Pardi et al. 2002; Matsuoka et al. 2006). Herein we found that a $50 \%$ reduction in maternal food intake in a rabbit model impaired placental structural phenotype (reduced length of decidua and labyrinth compartments) and led to placental pathology (such as atrophy or fibrosis). In contrast, placentas from pregnancies treated with sildenafil citrate showed significant changes when compared with those in the restricted group at the labyrinth zone (higher values of labyrinth ratio and absence of fibrosis process) and at the decidua compartment (increase in thickness and significant hyperplasia and hypertrophy of arterial sinuses). We can hypothesise that these changes are related to two main factors. First, it is known that sildenafil citrate acts as a potent angiogenesis stimulator (Pyriochou et al. 2007), increasing the growth of new vessels at the labyrinth (which is supported by the histological assessment, showing a higher number of small dilated capillaries when compared with untreated placentas). Concomitantly, a recent study from Luna et al. (2015) also found slight vasodilatation at the labyrinth zone in placentas of mice treated with this therapy. Second, the myometrium and the decidua vessels express high levels of PDE-5 (Buhimschi et al. 2004; Coppage et al. 2005) and, in the case of the rabbit, the placenta 
Group C
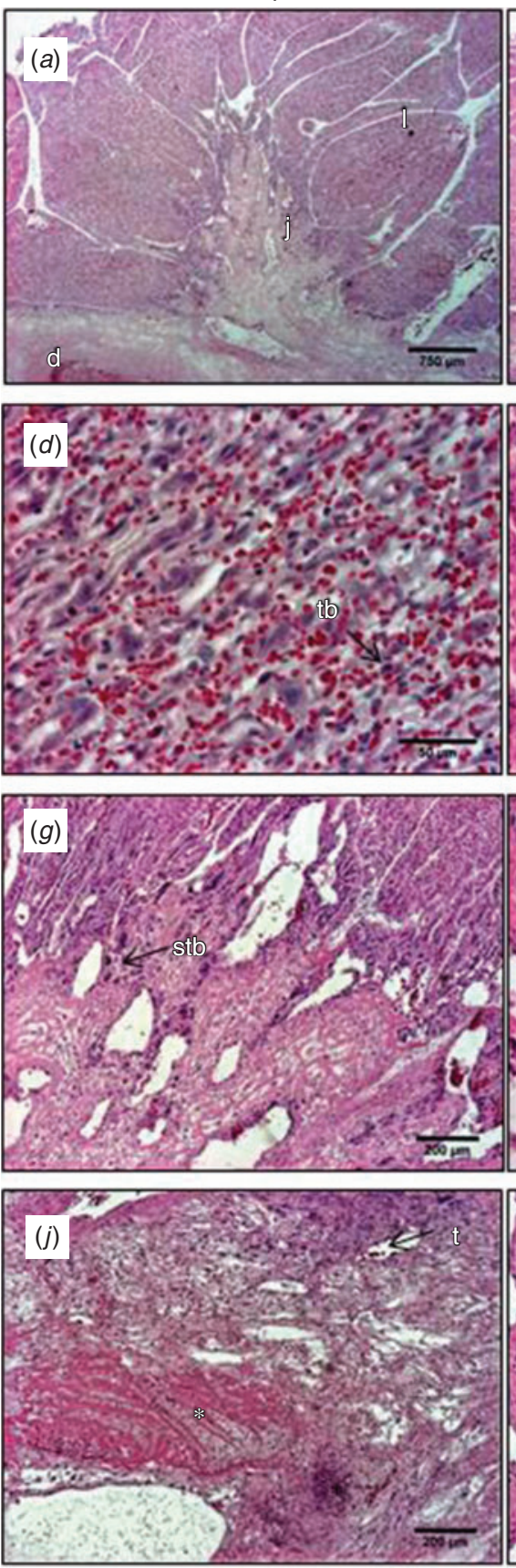

Group R

Group SC
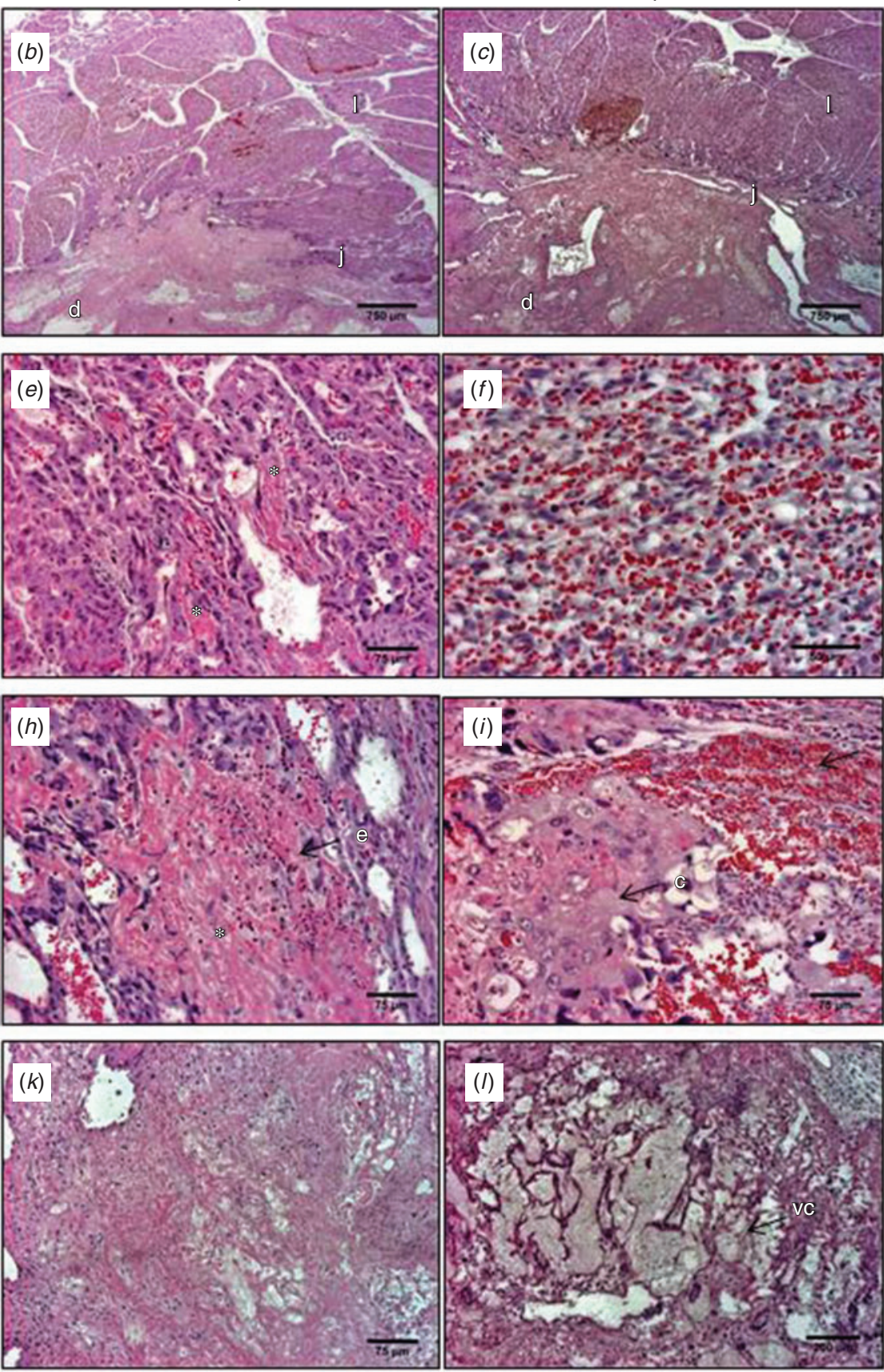

Fig. 1. Histological images of rabbit placenta at Day 28 of pregnancy in dams fed ad libitum (Group C), restricted diet (Group R) and restricted diet treated with sildenafil citrate (Group SC). $(a, b, c)$ The three parts of the rabbit's placenta (1, labyrinth; j, junctional zone and d, decidua) in each of the three experimental groups. $(d)$ Group C, normal trophoblast (tb) proliferation at the labyrinth zone. (e) Group R, vascular channels collapsed with multifocal areas of fibrosis $(*)$ and mineralisation at the labyrinth zone. $(f)$ Group SC, normal trophoblast proliferation at the labyrinth zone in a similar pattern to Group C. $(g)$ Group C, vascularisation at the junctional zone with normal trophoblast and syncytiotrophoblasts (stb). ( $h$ ) Group R, focus of sclerosis (*) at the junctional zone with inflammatory infiltrations (e) and decreased number of trophoblasts. (i) Group SC, junctional zone with syncytiotrophoblasts, increased vasculature with congestion $(\mathrm{c})$ and haemorrhagic foci. $(j)$ Group C, normal limits of the decidua with thrombi $(\mathrm{t})$ mineral and inflammation $(*)$. (k) Group R, decidua with necrosis, fibrin and few vascular channels. (l) Group SC, decidua with numerous dilated vascular channels (vc). 
Table 4. Feto-placental haemodynamics at Day 26 of pregnancy from dams fed ad libitum (C), restricted diet $(\mathrm{R})$ or restricted diet and treated with sildenafil citrate (SC)

Statistical analyses were performed by one-way ANOVA and $t$-test mean comparison test. Data represented as mean \pm s.e.m. ${ }^{\mathrm{a}, \mathrm{b}}$ Different superscripts within a row indicate significant differences between groups; $P<0.05$

\begin{tabular}{lcccc}
\hline Parameter & $\mathrm{C}(n=16)$ & $\mathrm{R}(n=16)$ & $\mathrm{SC}(n=16)$ & $P>\mathrm{f}$ \\
\hline Umbilical cord arteries & & & & \\
$\quad$ Resistance index & $0.70 \pm 0.02$ & $0.77 \pm 0.01$ & $0.77 \pm 0.05$ & 0.066 \\
$\quad$ Pulsatility index & $1.20 \pm 0.05$ & $1.25 \pm 0.04$ & $1.28 \pm 0.05$ & 0.468 \\
Systolic peak velocity & $33.20 \pm 4.05^{\mathrm{a}}$ & $42.60 \pm 3.46^{\mathrm{b}}$ & $43.90 \pm 3.35^{\mathrm{b}}$ & 0.012 \\
End diastolic velocity & $8.00 \pm 0.86$ & $10.30 \pm 1.16$ & $10.30 \pm 1.15$ & 0.336 \\
$\quad$ Time-averaged mean velocity & $20.60 \pm 2.37$ & $26.40 \pm 2.25$ & $27.10 \pm 2.17$ & 0.137 \\
Middle cerebral artery & & & & \\
$\quad$ Resistance index & $0.60 \pm 0.02^{\mathrm{a}}$ & $0.60 \pm 0.02^{\mathrm{a}}$ & $0.70 \pm 0.02^{\mathrm{b}}$ & 0.023 \\
$\quad$ Pulsatility index & $0.90 \pm 0.05^{\mathrm{a}}$ & $0.90 \pm 0.05^{\mathrm{a}}$ & $1.10 \pm 0.05^{\mathrm{b}}$ & 0.013 \\
Systolic peak velocity & $17.10 \pm 2.21^{\mathrm{a}}$ & $22.20 \pm 1.94^{\mathrm{b}}$ & $26.30 \pm 2.02^{\mathrm{b}}$ & 0.015 \\
End diastolic velocity & $6.50 \pm 0.63$ & $8.30 \pm 0.78$ & $7.70 \pm 0.46$ & 0.165 \\
Time-averaged mean velocity & $11.80 \pm 1.40^{\mathrm{a}}$ & $15.30 \pm 1.28^{\mathrm{b}}$ & $17.00 \pm 1.13^{\mathrm{b}}$ & 0.026 \\
\hline
\end{tabular}

Table 5. Morphometric measurements of newborns from dams fed ad libitum $(\mathrm{C})$, restricted diet $(\mathrm{R})$ or restricted diet and treated with sildenafil citrate (SC)

Statistical analyses were performed by one-way ANOVA and $t$-test mean comparison test. Data represented as mean \pm s.e.m. IUGR rate defined as those fetuses under 10th percentile of ad libitum control weights $(37.9 \mathrm{~g})$ estimated by a $\chi^{2}$ test. ${ }^{\mathrm{a}, \mathrm{b}, \mathrm{c}}$ Different superscripts within a row indicate significant differences between groups; $P<0.05$

\begin{tabular}{lcccc}
\hline Parameter & $\mathrm{C}(n=85)$ & $\mathrm{R}(n=75)$ & $\mathrm{SC}(n=76)$ & $P>\mathrm{f}$ \\
\hline Bodyweight (g) & $55.23 \pm 1.11^{\mathrm{a}}$ & $49.46 \pm 1.18^{\mathrm{b}}$ & $47.80 \pm 1.19^{\mathrm{b}}$ & 0.001 \\
$\begin{array}{l}\text { Biparietal } \\
\text { diameter (cm) }\end{array}$ & $2.20 \pm 0.01^{\mathrm{a}}$ & $2.08 \pm 0.01^{\mathrm{b}}$ & $2.15 \pm 0.01^{\mathrm{c}}$ & 0.001 \\
$\begin{array}{l}\text { Crown-rump } \\
\text { length (cm) }\end{array}$ & $11.00 \pm 0.09^{\mathrm{a}}$ & $10.20 \pm 0.09^{\mathrm{b}}$ & $10.50 \pm 0.10^{\mathrm{c}}$ & 0.001 \\
$\begin{array}{c}\text { Thoracic } \\
\text { diameter (cm) }\end{array}$ & $2.40 \pm 0.02^{\mathrm{a}}$ & $2.17 \pm 0.02^{\mathrm{b}}$ & $2.28 \pm 0.02^{\mathrm{c}}$ & 0.001 \\
\begin{tabular}{l} 
IUGR rate (\%) \\
\hline
\end{tabular} & $9.41^{\mathrm{a}}$ & $38.66^{\mathrm{b}}$ & $25.00^{\mathrm{c}}$ & 0.001 \\
\hline
\end{tabular}

has a high expression level of NOS, especially NOS3 (Khan et al. 2012), which may facilitate sildenafil citrate function. Both processes would be expected to stimulate neoangiogenesis and may also improve maternal blood flow to the placenta, thereby facilitating nutrient and oxygen delivery to the fetus.

Consequently, fetal growth was improved in terms of crownrump length and biparietal and thoracic diameters, at Day 28 and at birth. These findings support previous results from SánchezAparicio et al. (2008) and Stanley et al. (2012). However, this larger body size was not concomitant with increases in fetal weight, supporting data from previous studies in rodent models (Ramesar et al. 2010; George et al. 2013; Motta et al. 2015). Notwithstanding, studies in sheep with $50 \%$ food restriction (similar to our restriction) have shown that sildenafil citrate treatment increased fetal weight by $14 \%$ (Satterfield et al. 2010). Such disagreement may be related to differences in nutrient partitioning between monotocous and polytocous species (Fowden and Moore 2012), the capacity of the placenta to adapt its phenotype or function to undernutrition and the length of sildenafil citrate therapy (a total of 87 days, from Day 28 to Day 115 of pregnancy, Satterfield et al. 2010).

A remarkable finding of this novel study using a rabbit model comes from the results obtained by assessing the relative growth of fetal organs with respect to fetal weight, which may set the basis for future studies on the use of sildenafil citrate therapies and its impact on fetal organs. Fetuses treated with sildenafil citrate developed a proportionally larger liver with respect to the other two groups. This observation is in line with results obtained in rats (Pellicer et al. 2011). It is well known that from early development the liver is vital for health and body physiology. It participates in fat deposition (Godfrey et al. 2012), regulates growth and metabolism by modulating hormones and growth factors (Hellerstein and Munro 1994; Tchirikov et al. 2002) and is responsible for gluconeogenesis (Burns et al. 1997), the latter of which could explain the high glucose level found in the SC group. But, even more importantly, the liver can also modulate blood distribution as it is the first organ to receive blood from the placenta (Tchirikov et al. 2002) and, due to the presence of the ductus venosus, may distribute blood towards essential organs at the expense of less-essential organs (Cohn et al. 1974; Jensen et al. 1991). As a result of alterations in the liver, blood distribution may have changed, favouring developmental adaptation in the fetus by selectively increasing blood flow to vital organs like the brain ('brain-sparing effect').

The data obtained in the present study support the idea that undernutrition early in pregnancy may affect vital organs leading to disproportionate growth of the fetus (Bauer et al. 2003; Desai et al. 2007) and that the fetus can counteract this by an innate mechanism of fetal cardiac output distribution (Giussani 2011). In the present study, restricted fetuses showed higher head and brain mass relative to bodyweight, which suggests asymmetric growth retardation of the fetus, supporting the idea of the 'thrifty phenotype' (Wells 2011). Also, these data support previous studies in which the comparison of the brain weight to liver weight ratio was associated with undernutrition and dysmaturity (Anderson 1972; Camm et al. 2010). However, 
the results obtained by dividing these weights suggest that therapy with sildenafil citrate could ameliorate this ratio. Another finding in this study is that, although this brain-sparing effect has been proposed to be stimulated by the hypoglycaemic status in the restricted fetus (Giussani 2011), data obtained in this rabbit model suggest that there may be factors in addition to fetal glycaemic status that contribute.

Assessment of blood flow by Doppler ultrasonography at Day 26 of pregnancy showed that food restriction induced changes in the haemodynamic patterns of the fetus. Those IUGR fetuses exhibited a trend to increase the umbilical artery resistance index and demonstrated a significant increase in the systolic peak velocity, suggesting a deterioration of placental function (Carr et al. 2012). These blood-flow changes could not be rescued by sildenafil citrate, which is contrary to data from previous studies (Dastjerdi et al. 2012; Lin et al. 2012; Stanley et al. 2012; Trapani et al. 2015). As a consequence of the placental dysfunction and reduction in oxygen levels, the middle cerebral artery in both restricted and sildenafil-treated fetuses exhibited changes in the systolic mean velocity and therefore increased mean velocity values, which agrees with previous data on the middle cerebral artery of fetuses affected by IUGR (Hanif et al. 2007; Mari et al. 2007).

Nevertheless, fetuses undergoing sildenafil citrate therapy showed elevated values of pulsatility and resistance indexes, as Dastjerdi et al. (2012) found in pregnant women, which may suggest a certain grade of vasoconstriction (low indices reflects redistribution of cardiac output to the brain; Mari et al. 2007). It is known that cerebral neurons and vessels have high concentrations of PDE-5 (Kotera et al. 2000; Lin et al. 2006) and that sildenafil citrate can cross the placenta (Pellicer et al. 2011). Moreover, this therapy can increase brain cGMP levels (Zhang et al. 2002) and cerebral blood flow (Li et al. 2007). Taken together, these data suggest that fetuses from sildenafil-treated mothers activate a protective mechanism in the middle cerebral artery to counteract an excess in blood-flow supply that could produce cerebral oedema and consequent adverse neurological outcomes. However, these data should be interpreted with caution, as the Doppler assessment was only performed once during the pregnancy, and thus other possible changes in gestation could not be determined in response to sildenafil citrate in this study. Further studies are needed to determine the possible risks of blood overflow in the fetal brain and also to identify the mechanism by which the fetus is able to adapt its cerebral arterial vascular tone; this process possibly depends on the enhancement of nitric oxide abundance with sildenafil citrate administration. Furthermore, elucidating whether these haemodynamic and morphologic adaptations of the fetus can have consequences in adult life should be the focus of future investigations.

In summary, the results of the present study suggest that, in rabbits, a $50 \%$ restriction of maternal food intake is a valid model for inducing IUGR and placental insufficiency. Such effects can be partially counteracted by the administration of sildenafil citrate, since it improves reductions in perinatal body size and modifies placental growth and vascularisation in the labyrinth and decidua. Therefore, size of the newborns can be partially improved. Thus, our study sets the basis of further studies investigating the use of PDE-5 inhibitors to study organ development and the programming of offspring growth and postnatal homeostasis (in particular brain and liver function).

\section{Acknowledgements}

The authors thank MSc. Formoso-Rafferty, MSc. Bermejo-Poza, Mrs. M. Perez-Solana, Dr Villarroel, Dr Sferruzzi-Perri and Dr Kyle for their support. J. L.-T., M. A.-A., R. M.G.-G., P. L. L., A. G.-B. and P. G. R. are members of the EU COST Action FA1201 'Epigenetics and Periconception Environment (EPICONCEPT)'. J. L.-T., M. A.-A., R. M.G.-G., P. L. L., S. A., A. G.-B. and P. G. R. are members of the EU COST Action BM1308 'Sharing Advances on Large Animal Models (SALAAM)'. This research was supported by funding from the Spanish Ministry of Science and Technology (AGL2011-23822) and Comunidad de Madrid (S2013/ABI-2913).

\section{References}

Anderson, J. M. (1972). Increased brain weight-liver weight ratio as a necropsy sign of intrauterine undernutrition. J. Clin. Pathol. 25, 867-871. doi:10.1136/JCP.25.10.867

Bauer, R., Walter, B., Brust, P., Fuchtner, F., and Zwiener, U. (2003). Impact of asymmetric intrauterine growth restriction on organ function in newborn piglets. Eur. J. Obstet. Gynecol. Reprod. Biol. 110(Suppl 1), S40-S49. doi:10.1016/S0301-2115(03)00171-4

Beaudoin, S., Barbet, P., and Bargy, F. (2003). Developmental stages in the rabbit embryo: guidelines to choose an appropriate experimental model. Fetal Diagn. Ther. 18, 422-427. doi:10.1159/000073136

Buhimschi, C. S., Garfield, R. E., Weiner, C. P., and Buhimschi, I. A. (2004). The presence and function of phosphodiesterase type 5 in the rat myometrium. Am. J. Obstet. Gynecol. 190, 268-274. doi:10.1016/ J.AJOG.2003.07.006

Burns, S. P., Desai, M., Cohen, R. D., Hales, C. N., Iles, R. A., Germain, J. P., Going, T. C., and Bailey, R. A. (1997). Gluconeogenesis, glucose handling and structural changes in livers of the adult offspring of rats partially deprived of protein during pregnancy and lactation. J. Clin. Invest. 100, 1768-1774. doi:10.1172/JCI119703

Camm, E. J., Hansell, J. A., Kane, A. D., Herrera, E. A., Lewis, C., Wong, S., Morrell, N. W., and Giussani, D. A. (2010). Partial contributions of developmental hypoxia and undernutrition to prenatal alterations in somatic growth and cardiovascular structure and function. Am. J. Obstet. Gynecol. 203, 495.e24-495.e34. doi:10.1016/J.AJOG.2010.06.046

Carr, D. J., Aitken, R. P., Milne, J. S., David, A. L., and Wallace, J. M. (2012). Feto-placental biometry and umbilical artery Doppler velocimetry in the overnourished adolescent model of fetal growth restriction. Am. J. Obstet. Gynecol. 207, 141.e6-141.e15. doi:10.1016/J.AJOG.2012.05.008

Cauli, O., Herraiz, S., Pellicer, B., Pellicer, A., and Felipo, V. (2010). Treatment with sildenafil prevents impairment of learning in rats born to pre-eclamptic mothers. Neuroscience 171, 506-512. doi:10.1016/ J.NEUROSCIENCE.2010.08.065

Chuang, A. T., Strauss, J. D., Murphy, R. A., and Steers, W. D. (1998). Sildenafil, a type-5 cGMP phosphodiesterase inhibitor, specifically amplifies endogenous cGMP-dependent relaxation in rabbit corpus cavernosum smooth muscle in vitro. J. Urol. 160, 257-261. doi:10.1016/S00225347(01)63100-8

Cohn, H. E., Sacks, E. J., Heymann, M. A., and Rudolph, A. M. (1974). Cardiovascular responses to hypoxemia and acidemia in fetal lambs. Am. J. Obstet. Gynecol. 120, 817-824. doi:10.1016/0002-9378(74)90587-0

Coppage, K. H., Sun, X., Baker, R. S., and Clark, K. E. (2005). Expression of phosphodiesterase 5 in maternal and fetal sheep. Am. J. Obstet. Gynecol. 193, 1005-1010. doi:10.1016/J.AJOG.2005.05.054

Dastjerdi, M. V., Hosseini, S., and Bayani, L. (2012). Sildenafil citrate and utero-placental perfusion in fetal growth restriction. J. Res. Med. Sci. 17, $632-636$. 
Derrick, M., Drobyshevsky, A., Ji, X., Chen, L., Yang, Y., Ji, H., Silverman, R. B., and Tan, S. (2009). Hypoxia-ischemia causes persistent movement deficits in a perinatal rabbit model of cerebral palsy: assessed by a new swim test. Int. J. Dev. Neurosci. 27, 549-557. doi:10.1016/ J.IJDEVNEU.2009.06.008

Desai, M., Gayle, D., Babu, J., and Ross, M. G. (2007). The timing of nutrient restriction during rat pregnancy/lactation alters metabolic syndrome phenotype. Am. J. Obstet. Gynecol. 196, 555.e1-555.e7. doi:10.1016/ J.AJOG.2006.11.036

Dilworth, M. R., Andersson, I., Renshall, L. J., Cowley, E., Baker, P., Greenwood, S., Sibley, C. P., and Wareing, M. (2013). Sildenafil citrate increases fetal weight in a mouse model of fetal growth restriction with a normal vascular phenotype. PLoS One 8, e77748. doi:10.1371/ JOURNAL.PONE.0077748

Eixarch, E., Figueras, F., Hernandez-Andrade, E., Crispi, F., Nadal, A., Torre, I., Oliveira, S., and Gratacos, E. (2009). An experimental model of fetal growth restriction based on selective ligature of uteroplacental vessels in the pregnant rabbit. Fetal Diagn. Ther. 26, 203-211. doi: $10.1159 / 000264063$

Fischer, B., Chavatte-Palmer, P., Viebahn, C., Navarrete Santos, A., and Duranthon, V. (2012). Rabbit as a reproductive model for human health. Reproduction 144, 1-10. doi:10.1530/REP-12-0091

Fowden, A. L., and Moore, T. (2012). Maternal-fetal resource allocation: co-operation and conflict. Placenta 33(Suppl 2), e11-e15. doi:10.1016/J.PLACENTA.2012.05.002

Ganzevoort, W., Alfirevic, Z., von Dadelszen, P., Kenny, L., Papageorghiou, A., van Wassenaer-Leemhuis, A., Gluud, C., Mol, B. W., and Baker, P. N. (2014). STRIDER: Sildenafil therapy in dismal prognosis early-onset intrauterine growth restriction - a protocol for a systematic review with individual participant data and aggregate data meta-analysis and trial sequential analysis. Syst. Rev. 3, 23. doi:10.1186/2046-4053-3-23

George, E. M., Palei, A. C., Dent, E. A., and Granger, J. P. (2013). Sildenafil attenuates placental ischemia-induced hypertension. Am. J. Physiol. Regul. Integr. Comp. Physiol. 305, R397-R403. doi:10.1152/AJPREGU.00216 2013

Ghidini, A. (1996). Idiopathic fetal growth restriction: a pathophysiologic approach. Obstet. Gynecol. Surv. 51, 376-382. doi:10.1097/00006254199606000-00023

Giussani, D. A. (2011). The vulnerable developing brain. Proc. Natl. Acad. Sci. USA 108, 2641-2642. doi:10.1073/PNAS.1019726108

Godfrey, K. M., Haugen, G., Kiserud, T., Inskip, H. M., Cooper, C., Harvey, N. C., Crozier, S. R., Robinson, S. M., Davies, L., and Hanson, M. A. (2012). Fetal liver blood-flow distribution: role in human developmental strategy to prioritise fat deposition versus brain development. PLoS One 7, e41759. doi:10.1371/JOURNAL.PONE.0041759

Hanif, F., Drennan, K., and Mari, G. (2007). Variables that affect the middle cerebral artery peak systolic velocity in fetuses with anaemia and intrauterine growth restriction. Am. J. Perinatol. 24, 501-505. doi: $10.1055 /$ S-2007-986683

Hellerstein, M. K., and Munro, H. N. (1994). Interaction of liver, muscle and adipose tissue in the regulation of metabolism in response to nutritional and other factors. In 'The Liver: Biology and Pathobiology'. (Ed(s) I. M. Arias, J. L. Boyer, N. Fausto.) pp. 1169-1191. (Raven Press: New York.)

Jensen, A., Roman, C., and Rudolph, A. M. (1991). Effects of reducing uterine blood flow on fetal blood-flow distribution and oxygen delivery. J. Dev. Physiol. 15, 309-323.

Khan, H., Kusakabe, K. T., Wakitani, S., Hiyama, M., Takeshita, A., and Kiso, Y. (2012). Expression and localisation of NO synthase isoenzymes (iNOS and eNOS) in development of the rabbit placenta. J. Reprod. Dev. 58, 231-236. doi:10.1262/JRD.11-128T

Kobayashi, T., Ito, T., and Shiomi, M. (2011). Roles of the WHHL rabbit in translational research on hypercholesterolemia and cardiovascular diseases. J. Biomed. Biotechnol. 2011, 406473. doi:10.1155/2011/406473
Kotera, J., Fujishige, K., and Omori, K. (2000). Immunohistochemical localisation of cGMP-binding cGMP-specific phosphodiesterase (PDE5) in rat tissues. J. Histochem. Cytochem. 48, 685-693. doi:10.1177/002215540004800512

Lacassie, H. J., Germain, A. M., Valdes, G., Fernandez, M. S., Allamand, F., and Lopez, H. (2004). Management of Eisenmenger syndrome in pregnancy with sildenafil and L-arginine. Obstet. Gynecol. 103, 11181120. doi:10.1097/01.AOG.0000125148.82698.65

Lecarpentier, E., Morel, O., Tarrade, A., Dahirel, M., Bonneau, M., Gayat, E., Evain-Brion, D., Chavatte-Palmer, P., and Tsatsaris, V. (2012) Quantification of utero-placental vascularisation in a rabbit model of IUGR with three-dimensional power Doppler angiography. Placenta 33 769-775, doi:10.1016/J.PLACENTA.2012.06.013

Lesage, J., Blondeau, B., Grino, M., Breant, B., and Dupouy, J. P. (2001). Maternal undernutrition during late gestation induces fetal overexposure to glucocorticoids and intrauterine growth retardation, and disturbs the hypothalamo-pituitary-adrenal axis in the newborn rat. Endocrinology 142, 1692-1702.

Li, L., Jiang, Q., Zhang, L., Ding, G., Gang Zhang, Z., Li, Q., Ewing, J. R., Lu, M., Panda, S., Ledbetter, K. A., Whitton, P. A., and Chopp, M (2007). Angiogenesis and improved cerebral blood flow in the ischemic boundary area detected by MRI after administration of sildenafil to rats with embolic stroke. Brain Res. 1132, 185-192. doi:10.1016/ J.BRAINRES.2006.10.098

Lin, C. S., Lin, G., Xin, Z. C., and Lue, T. F. (2006). Expression, distribution and regulation of phosphodiesterase 5. Curr. Pharm. Des. 12, 3439-3457. doi: $10.2174 / 138161206778343064$

Lin, T. H., Su, Y. N., Shih, J. C., Hsu, H. C., and Lee, C. N. (2012) Resolution of high uterine artery pulsatility index and notching following sildenafil citrate treatment in a growth-restricted pregnancy. Ultrasound Obstet. Gynecol. 40, 609-610. doi:10.1002/UOG.11142

López-Tello, J., Barbero, A., González-Bulnes, A., Astiz, S., Rodríguez, M., Formoso-Rafferty, N., Arias-Álvarez, M., and Rebollar, P. G. (2015). Characterisation of early changes in feto-placental haemodynamics in a diet-induced rabbit model of IUGR. J. Dev. Orig. Health Dis. 6, 454-461. doi:10.1017/S2040174415001385

Luna, R. L., Nunes, A. K., Oliveira, A. G., Araujo, S. M., Lemos, A. J., Rocha, S. W., Croy, B. A., and Peixoto, C. A. (2015). Sildenafil (Viagra) blocks inflammatory injury in LPS-induced mouse abortion: a potential prophylactic treatment against acute pregnancy loss? Placenta 36, 1122-1129. doi:10.1016/J.PLACENTA.2015.07.133

Malassiné, A., Frendo, J. L., and Evain-Brion, D. (2003). A comparison of placental development and endocrine functions between the human and mouse model. Hum. Reprod. Update 9, 531-539. doi:10.1093/ HUMUPD/DMG043

Mari, G., Hanif, F., Kruger, M., Cosmi, E., Santolaya-Forgas, J., and Treadwell, M. C. (2007). Middle cerebral artery peak systolic velocity: a new Doppler parameter in the assessment of growth-restricted fetuses. Ultrasound Obstet. Gynecol. 29, 310-316. doi:10.1002/UOG.3953

Maršál, K. (2002). Intrauterine growth restriction. Curr. Opin. Obstet. Gynecol. 14, 127-135. doi:10.1097/00001703-200204000-00005

Matsuoka, T., Mizoguchi, Y., Serizawa, K., Ishikura, T., Mizuguchi, H., and Asano, Y. (2006). Effects of stage and degree of restricted feeding on pregnancy outcome in rabbits. J. Toxicol. Sci. 31, 169-175. doi:10.2131/ JTS.31.169

Motta, C., Grosso, C., Zanuzzi, C., Molinero, D., Picco, N., Bellingeri, R., Alustiza, F., Barbeito, C., Vivas, A., and Romanini, M. C. (2015). Effect of Sildenafil on pre-eclampsia-like mouse model induced by L-name. Reprod. Domest. Anim. 50, 611-616. doi:10.1111/RDA.12536

Nardozza, L. M., Araujo Junior, E., Barbosa, M. M., Caetano, A. C., Lee, D. J., and Moron, A. F. (2012). Fetal growth restriction: current knowledge to the general Obs/Gyn. Arch. Gynecol. Obstet. 286, 1-13. doi:10.1007/ S00404-012-2330-6 
Panda, S., Das, A., and Nowroz, H. M. (2014). Sildenafil citrate in fetal growth restriction. J. Reprod. Infertil. 15, 168-169.

Pardi, G., Marconi, A. M., and Cetin, I. (2002). Placental-fetal interrelationship in IUGR fetuses - a review. Placenta 23, S136-S141. doi:10.1053/ PLAC.2002.0802

Park, J. Y., Son, H., Kim, S. W., and Paick, J. S. (2004). Potentiation of apomorphine effect on sildenafil-induced penile erection in conscious rabbits. Asian J. Androl. 6, 205-209.

Pellicer, B., Herraiz, S., Cauli, O., Rodrigo, R., Asensi, M., Cortijo, J., Serra, V., Morcillo, E., Felipo, V., Simón, C., and Pellicer, A. (2011). Haemodynamic effects of long-term administration of sildenafil in normotensive pregnant and non-pregnant rats. BJOG 118, 615-623. doi:10.1111/J.1471-0528.2010.02839.X

Polisca, A., Scotti, L., Orlandi, R., Brecchia, G., and Boiti, C. (2010). Doppler evaluation of maternal and fetal vessels during normal gestation in rabbits. Theriogenology 73, 358-366. doi:10.1016/J.THERIOGEN OLOGY.2009.09.019

Purcell, T. L., Given, R., Chwalisz, K., and Garfield, R. E. (1999). Nitric oxide synthase distribution during implantation in the mouse. Mol. Hum. Reprod. 5, 467-475. doi:10.1093/MOLEHR/5.5.467

Püschel, B., Daniel, N., Bitzer, E., Blum, M., Renard, J. P., and Viebahn, C. (2010). The rabbit (Oryctolagus cuniculus): a model for mammalian reproduction and early embryology. Cold Spring Harb. Protoc. doi:10.1101/PDB.EMO139

Pyriochou, A., Zhou, Z., Koika, V., Petrou, C., Cordopatis, P., Sessa, W. C., and Papapetropoulos, A. (2007). The phosphodiesterase 5 inhibitor sildenafil stimulates angiogenesis through a protein kinase G/MAPK pathway. J. Cell. Physiol. 211, 197-204. doi:10.1002/JCP.20929

Ramesar, S. V., Mackraj, I., Gathiram, P., and Moodley, J. (2010). Sildenafil citrate improves fetal outcomes in pregnant, L-NAME-treated, SpragueDawley rats. Eur. J. Obstet. Gynecol. Reprod. Biol. 149, 22-26. doi:10.1016/J.EJOGRB.2009.11.005

Rebollar, P. G., Dal Bosco, A., Millán, P., Cardinali, R., Brecchia, G., Sylla, L., Lorenzo, P. L., and Castellini, C. (2012). Ovulating induction methods in rabbit does: the pituitary and ovarian responses. Theriogenology 77, 292-298. doi:10.1016/J.THERIOGENOLOGY.2011.07.041

Reynolds, S. R. (1946). The relation of hydrostatic conditions in the uterus to the size and shape of the conceptus during pregnancy; a concept of uterine accommodation. Anat. Rec. 95, 283-296. doi:10.1002/AR.1090950303

Ross, M. G., and Desai, M. (2013). Developmental programming of offspring obesity, adipogenesis and appetite. Clin. Obstet. Gynecol. 56, 529-536. doi:10.1097/GRF.0B013E318299C39D

Samuel, C. A., Jack, P. M., and Nathanielsz, P. W. (1975). Ultrastructural studies of the rabbit placenta in the last third of gestation. J. Reprod. Fertil. 45, 9-14. doi:10.1530/JRF.0.0450009
Sánchez-Aparicio, P., Mota-Rojas, D., Nava-Ocampo, A. A., TrujilloOrtega, M. E., Alfaro-Rodríguez, A., Arch, E., and AlonsoSpilsbury, M. (2008). Effects of sildenafil on the fetal growth of guinea pigs and their ability to survive induced intrapartum asphyxia. Am. J. Obstet. Gynecol. 198, 127.e1-127.e6. doi:10.1016/ J.AJOG.2007.06.068

Sankaran, S., and Kyle, P. M. (2009). Aetiology and pathogenesis of IUGR. Best Pract. Res. Clin. Obstet. Gynaecol. 23, 765-777. doi:10.1016/ J.BPOBGYN.2009.05.003

Satterfield, M. C., Bazer, F. W., Spencer, T. E., and Wu, G. (2010). Sildenafil citrate treatment enhances amino acid availability in the conceptus and fetal growth in an ovine model of intrauterine growth restriction. J. Nutr. 140, 251-258. doi:10.3945/JN.109.114678

Schroder, H. J. (2003). Models of fetal growth restriction. Eur. J. Obstet. Gynecol. Reprod. Biol. 110(Suppl 1), S29-S39. doi:10.1016/S03012115(03)00170-2

Serrano, N. C., Casas, J. P., Diaz, L. A., Paez, C., Mesa, C. M., Cifuentes, R., Monterrosa, A., Bautista, A., Hawe, E., Hingorani, A. D., Vallance, P., and Lopez-Jaramillo, P. (2004). Endothelial NO synthase genotype and risk of pre-eclampsia: a multicentre case-control study. Hypertension 44, 702-707. doi:10.1161/01.HYP.0000143483.66701.EC

Stanley, J. L., Andersson, I. J., Poudel, R., Rueda-Clausen, C. F., Sibley, C. P., Davidge, S. T., and Baker, P. N. (2012). Sildenafil citrate rescues fetal growth in the catechol-o-methyl transferase knockout mouse model. Hypertension 59, 1021-1028. doi:10.1161/HYPERTENSIONAHA. 111.186270

Sun, X., Wang, K., Wang, W., and Li, B. (2014). Clinical study on sildenafil in treatment of pregnant women with pulmonary arterial hypertension. Zhonghua Fu Chan Ke Za Zhi 49, 414-418.

Tchirikov, M., Kertschanska, S., Sturenberg, H. J., and Schroder, H. J. (2002). Liver blood perfusion as a possible instrument for fetal growth regulation. Placenta 23(Suppl A), S153-S158. doi:10.1053/PLAC. 2002.0810

Trapani, A. J., Goncalves, L. F., Trapani, T. F., Franco, M. J., Galluzzo, R. N., and Pires, M. M. (2015). Comparison between transdermal nitroglycerin and sildenafil citrate in intrauterine growth restriction: effect on uterine, umbilical and fetal middle cerebral artery pulsatility index. Ultrasound Obstet. Gynecol. doi:10.1002/UOG.15673

Wells, J. C. (2011). The thrifty phenotype: an adaptation in growth or metabolism? Am. J. Hum. Biol. 23, 65-75. doi:10.1002/AJHB. 21100

Zhang, R., Wang, Y., Zhang, L., Zhang, Z., Tsang, W., Lu, M., and Chopp, M. (2002). Sildenafil (Viagra) induces neurogenesis and promotes functional recovery after stroke in rats. Stroke 33, 2675-2680. doi:10.1161/01.STR.0000034399.95249.59 